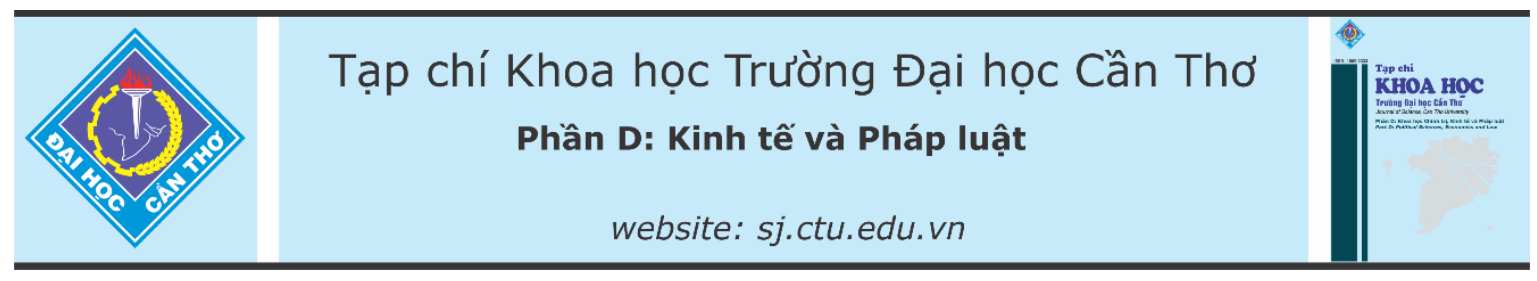

DOI:10.22144/ctu.jvn.2021.165

\title{
TÁC ĐỘNG CỦA HIỆU QUẢ QUẢN TRI NHÀ NƯỚC ĐẾN THU HÚT VỐN ĐẦU TU’ TRỰC TIỂP NƯỚC NGOÀI Ở CÁC QUỐC GIA ĐÔNG NAM Á
}

\author{
Trần Cương ${ }^{1 *}$ và Phạm Duy $\mathrm{Anh}^{2}$ \\ ${ }^{1}$ Sở Kế hoạch và Đầu tur tỉnh Tiền Giang \\ ${ }^{2}$ Công ty TNHH MTV Cấp nuoớc Tiền Giang \\ *Nguời chịu trách nhiệm về bài viết: Trần Cuơng (email: cuong.tr.vn@gmail.com)
}

\section{Thông tin chung:}

Ngày nhận bài: 19/05/2021

Ngày nhận bài sưa: 06/07/2021

Ngày duyệt đăng: 29/10/2021

Title:

Impact of the quality of Governance on FDI Inflows:

Empirical Evidence from

ASEAN Countries

\section{Tù khóa:}

Đầu tư trực tiếp nước ngoài, độ mở nền kinh tế, nguồn lực tụ nhiên, quản trị nhà nuoóc, quy mô thị truờng

\section{Keywords:}

Foreign direct investment, governance indicators, market size, natural resources, openness

\begin{abstract}
The purpose of this paper is to investigate the effect of governance indicators (political stability, control of corruption, rule of law, regularity quality, voice and accountability and government effectiveness) on foreign direct investment (FDI) inflows to Asian countries. The authors employed an unbalanced panel regression model on data from Asian countries for the period 2000 to 2018. While controlling for standard FDI variables, the results provide that the political stability and absence of violence, voice and accountability, government effectiveness are correlated with FDI.
\end{abstract}

\section{TÓM TÁ́T}

Mục tiêu của nghiên cứu là xác định tác động của hiệu quả quản trị nhà nuớc (bao gồm: ổn định chính trị, kiểm soát tham nhũng, pháp quyền, chất luợng điều hành, quyền phát ngôn và trách nhiệm giải trình, hiệu quả chính quyền) đến thu hút vốn đầu tu trục tiếp nước ngoài ở các quốc gia Đông Nam Á giai đoạn 2000-2018. Khi kiểm soát các yếu tố khác có tác động đến FDI, kết quả nghiên cưu đã cho thấy sư ổn định chinh trị, quyền phát ngôn và trách nhiệm giải trình, hiệu quả chính quyền là nhũng yếu tố có ảnh hưởng đến thu hút vốn đầu tu trực tiếp nước ngoài ở các quốc gia Đông Nam Á trong giai đoạn nghiên cưu.

\section{GIỚI THIỆU}

Vốn đầu tư trực tiếp nước ngoài (foreign direct investment - FDI) là một yếu tố quan trọng có tác động tích cực đến tăng trưởng kinh tế các quốc gia, đặc biệt là ở các quốc gia đang phát triển, vì FDI vừa giúp bổ sung nguồn vốn đầu tư, vừa thúc đẩy phát triển khoa học công nghệ thông qua quá trình lan tỏa công nghệ (Bénassy-Quéré et al., 2007). Tuy nhiên, dòng vốn FDI cũng hết sức nhạy cảm với những rủi ro đến từ quốc gia nhận đầu tư, như sự kém hiệu quả của Chính phủ, sự đảo ngược chính sách và sự yếu kém trong việc bảo vệ quyền tài sản của nhà đầu tư
(Wei, 2000). Song song đó, hiệu quả quản trị nhà nước được xem là yếu tố có thể tạo nên sự khác biệt trong tăng trưởng kinh tế và mức thu nhập bình quân đầu người giữa các quốc gia. Những quốc gia được đánh giá cao trong việc bảo vệ quyền công dân và quyền tài sản của công dân, cũng như có mức độ tự do kinh tế, tự do chính trị cao và mức độ tham nhũng thấp thường đạt được mức thịnh vượng cao hơn (International Monetary Fund [IMF], 2003).

Với tầm quan trọng của dòng vốn FDI trong thúc đẩy tăng trưởng và phát triển kinh tế, cũng như vai trò của hiệu quả quản trị nhà nước trong thu hút FDI, 
nhiều nghiên cứu thực nghiệm đã được tiến hành nhằm củng cố cho lập luận hiệu quả quản trị nhà nước có tác động tích cực đến thu hút FDI (BénassyQuéré et al., 2007; Biro et al., 2019; Gangi \& Abdulrazak, 2012; Gani, 2007; Globerman \& Shapiro, 2002; Kok \& Ersoy, 2009; Kurul \& Yalta, 2017; Li \& Filer, 2007; Mengistu \& Adhikary, 2011; Ross, 2019; Shah, 2014; Shah \& Afridi, 2015; Younsi \& Bechtini, 2019; Zeshan \& Talat, 2014; Zidi \& Ali, 2016). Tuy nhiên, không phải tất cả các nghiên cứu trước đều cho thấy hiệu quả quản trị nhà nước có tác động tích cực đến thu hút FDI. Một số nghiên cứu đã cho thấy các yếu tố phản ánh chất lượng kiểm soát tham nhũng, quyền phát ngôn và trách nhiệm giải trình, hay ổn định chính trị và không bạo động là những yếu tố có tác động tiêu cực đến thu hút FDI (Gangi \& Abdulrazak, 2012; Ross, 2019; Shah \& Afridi, 2015; Younsi \& Bechtini, 2019; Zidi \& Ali, 2016). Song song đó, trong một số nghiên cứu trước cũng không tìm thấy bằng chứng thực nghiệm thể hiện các yếu tố phản ánh hiệu quả chính quyền, pháp quyền, ổn định chính trị và không bạo động, chất lượng điều hành, quyền phát ngôn và trách nhiệm giải trình có tác động đến thu hút FDI (Biro et al., 2019; Gangi \& Abdulrazak, 2012; Gani, 2007; Kurul \& Yalta, 2017; Mengistu \& Adhikary, 2011; Shah \& Afridi, 2015). Mặc dù chủ đề tác động của hiệu quả quản trị nhà nước đến thu hút FDI nhận được khá nhiều sự quan tâm của các nhà hoạch định chính sách lẫn các nhà nghiên cứu trên thế giới, tuy nhiên kết quả lược khảo các nghiên cứu trước cũng chỉ ra sự thiếu vắng nghiên cứu đối với khu vực Đông Nam Á trong những năm gần đây, nơi đang trở thành điểm sáng trong thu hút FDI. Theo báo cáo đầu tư ASEAN 2019 được Ban Thư ký Hiệp hội các quốc gia Đông Nam Á (ASEAN) công bố, FDI vào ASEAN đã tăng năm thứ 3 liên tiếp, đạt mức kỷ lục 155 tỷ USD trong năm 2018, so với mức 147 tỷ USD năm trước đó. Tỷ lệ vốn FDI của ASEAN trong tổng lượng FDI toàn cầu cũng tăng từ $9,6 \%$ năm 2017 lên $11,5 \%$. Nếu nói thế kỷ XXI là thế kỷ của châu Á, thì khu vực Đông Nam của châu lục này (gồm có 11 quốc gia) đóng góp một động lực đáng kề. Xuất phát từ nền tảng lý thuyết và thực tiễn nêu trên, nghiên cứu này nhằm đánh giá tác động của hiệu quả quản trị nhà nước đến thu hút vốn FDI ở các quốc gia Đông Nam Á, trên cơ sở đó, đề xuất giải pháp để nâng cao hiệu quả quản trị nhà nước và tăng cường thu hút FDI vào các quốc gia Đông Nam Á trong thời gian tới.

\section{CƠ SỞ LÝ THUYẾT}

\subsection{Quản trị nhà nước}

Thuật ngữ "Quản trị nhà nước" (từ tiếng Anh là the quality of governance) bắt đầu được sử dụng từ thập niên 1990, gắn với quá trình cải cách khu vực công ở các nước và thực thi mô hình quản lý công mới. Theo Shah and Huther (1999), quản trị nhà nước là các khía cạnh thực hành quyền lực qua thể chế chính thức hoặc phi chính thức nhằm quản trị mọi nguồn tài nguyên đã giao cho nhà nước. Khái niệm "Quản trị nhà nước tốt" được nhắc đến nhiều vào thập niên 1990 trong bối cảnh toàn cầu hóa ngày càng mạnh mẽ và dân chủ hóa ngày càng mở rộng. Theo đó, quản trị nhà nước tốt là cách thức sử dụng sức mạnh quyền lực nhà nước để quản lý nguồn lực xã hội vì sự phát triển quốc gia (Shah \& Huther, 1999).

Nghiên cứu này sử dụng chỉ số quản trị toàn cầu (Worldwide Governance Indicators - WGI) được phát triển bởi Kaufmann et al. (1999) có giá trị thay đổi từ $-2,5$ đến $+2,5$ để đo lường hiệu quả quản trị nhà nước. Chỉ số WGIs là cơ sở dữ liệu về quản trị quốc gia của hơn 200 quốc gia và vùng lãnh thổ (bao gồm các quốc gia khu vực Đông Nam Á), gồm 6 chỉ số thành phần: (i) Quyền phát ngôn (của người dân) và trách nhiệm giải trình (của chính quyền) (voice and accountability); (ii) Ổn định chính trị và không bạo động (political stability and the absence of violence); (iii) Hiệu quả chính quyền (government effectiveness); (iv) Chất lượng điều hành (regulatory quality); (v) Pháp quyền (rule of law); (vi) Kiểm soát tham nhũng (control of corruption).

\section{2. Đầu tư trực tiếp nước ngoài}

FDI là hoạt động đầu tư được thực hiện nhằm đạt được những lợi ích lâu dài của một doanh nghiệp tại một nước khác (nước nhận đầu tư - hosting country) không phải nước mà doanh nghiệp đang hoạt động (nước đi đầu tư - source country) với mục đích quản lý một cách có hiệu quả doanh nghiệp (IMF, 1993). Trong khi đó, World Trade Organization [WTO] (1996) cho rằng FDI xảy ra khi một nhà đầu tư từ một nước (nước chủ đầu tư) có được một tài sản ở một nước khác (nước thu hút đầu tư) cùng với quyền quản lý tài sản đó. Phương diện quản lý là thứ để phân biệt FDI với các công cụ tài chính khác. Trong phần lớn trường hợp, cả nhà đầu tư lẫn tài sản mà người đó quản lý ở nước ngoài là các cơ sở kinh doanh. Trong những trường hợp đó, nhà đầu tư thường hay được gọi là "công ty mẹ" và các tài sản được gọi là "công ty con" hay "chi nhánh công ty". 


\subsection{Lý thuyết về đầu tư trực tiếp nước ngoài}

Lý thuyết thể chế (institutional theory) mô tả, giải thích và tiên đoán về sự xuất hiện, cũng như ảnh hưởng của các quy tắc, đồng thời xem xét cách thức thông qua việc thay đổi một số quy tắc nhất định có thể hỗ trợ hoặc cản trở những kết quả (Kasper \& Streit, 1998). Theo North (1990), lý thuyết thể chế cho rằng thể chế của quốc gia nhận đầu tư là yếu tố quan trọng, quy định các nguyên tắc, tiêu chuẩn mà các doanh nghiệp FDI phải thực hiện trong quá trình đầu tư, tìm kiếm lợi nhuận. Một quốc gia có chất lượng thể chế tốt sẽ giúp doanh nghiệp giảm thiểu được rủi ro trong quá trình đầu tư, sản xuất kinh doanh, tạo điều kiện thuận lợi để doanh nghiệp có thể tương tác một cách hiệu quả, qua đó góp phần giảm thiểu chi phí giao dịch, tăng lợi nhuận của doanh nghiệp. Do đó, theo lý thuyết thể chế, hiệu quả quản trị nhà nước tốt có thể được xem là một lợi thế để các quốc gia thu hút nhiều vốn FDI.

\subsection{Tác động của hiệu quả quản trị nhà nước đến đẩu tư trực tiếp nước ngoài}

Nghiên cứu của Globerman and Shapiro (2002) cho rằng hoạt động kinh tế của một quốc gia chịu ảnh hưởng bởi yếu tố chính trị, thể chế và môi tường pháp lý. Quốc gia có hiệu quả quản trị nhà nước tốt sẽ tạo điều kiện thuận lợi thúc đẩy tăng trưởng kinh tế, thu hút nhiều vốn đầu tư, trong đó có vốn FDI. Bên cạnh đó, Gani (2007) cho rằng kinh tế học thể chế mới đã mở rộng phạm vi của lý thuyết tân cổ điển, cho thấy các thể chế là nền tảng cho sự vận hành hiệu quả của các nền kinh tế dựa trên thị trường. Một trong số những khía cạnh phổ biến của thể chế là hiệu quả quản trị nhà nước. Hiệu quả quản trị nhà nước tốt sẽ thúc đẩy hợp tác kinh tế quốc tế, thu hút được sự quan tâm đầu tư của nhiều nhà đầu tư nước ngoài, qua đó làm tăng dòng vốn FDI chảy vào. Và trong nghiên cứu của Li and Filer (2007), các tác giả đã sử dụng mô hình thể chế để giải thích tác động của sự thay đổi hiệu quả quản trị nhà nước đến dòng vốn FDI. Các yếu tố bao gồm luật pháp, chính sách là các quy tắc trong xã hội và mỗi cá nhân vì muốn tối đa hóa lợi ích sẽ phải điều chỉnh hành vi cho phù hợp với các quy tắc. Theo đó, hiệu quả quản trị nhà nước có thể tạo điều kiện hoặc hạn chế hợp tác kinh tế quốc tế thông qua các khía cạnh công bằng, minh bạch, hiệu quả để bảo vệ quyền sở hữu và tuân thủ các hợp đồng đã ký kết, từ đó ảnh hưởng đến dòng vốn FDI.

Theo Bénassy-Quéré et al., (2007), vào cuối những năm 1990, nhiều nghiên cứu tập trung vào chủ đề tác động của hiệu quả quản trị nhà nước đến tăng trưởng và thu nhập bình quân đầu người ở các quốc gia. Theo đó, những quốc gia có chất lượng quyền bảo vệ dân sự và bảo vệ tài sản tốt, tự do về chính trị và mở rộng sản xuất kinh doanh, ít tham nhũng thì sẽ thịnh vượng hơn những quốc gia khác. Song song đó, theo Bénassy-Quéré et al., (2007), có ba lý do có thể diễn giải cho việc quốc gia có hiệu quả quản trị nhà nước tốt sẽ thu hút nhiều FDI. Thứ nhất, hiệu quả quản trị nhà nước tốt giúp nâng cao kỳ vọng năng suất; thứ hai, hiệu quả quản trị nhà nước kém sẽ làm tăng chi phí bổ sung, tiêu biểu là chi phí cho vấn đề tham nhũng; và cuối cùng, hiệu quả quản trị nhà nước kém, thể hiện qua các khía cạnh như Chính phủ kém hiệu quả, thường xuyên thay đổi chính sách, khả năng thực thi quyền sở hữu và pháp luật nói chung kém sẽ làm tăng chi phí chìm cho các nhà đầu tư trực tiếp nước ngoài.

Mengistu and Adhikary (2011) cho rằng FDI nhạy cảm với "rủi ro chính trị của quốc gia", nghĩa là các quốc gia có luật pháp và quy định hiệu quả trong việc bảo vệ quyền tài sản và quyền dân sự của nhà đầu tư nước ngoài sẽ dễ thu hút nguồn vốn FDI hơn và ngược lại. Đồng thời, FDI rất nhạy cảm với chi phí giao dịch của các khoản đầu tư, tức là FDI có xu hướng chảy vào những quốc gia nơi mà các nhà đầu tư có thể nhận được đầy đủ lợi nhuận từ các khoản đầu tư của họ. Nói cách khác, tính minh bạch và trách nhiệm giải trình trong hoạt động, tình trạng thực thi pháp luật trong trường hợp vi phạm các quy tắc và hợp đồng, và điều kiện kinh doanh dễ dàng được coi là các biến số quản trị nhà nước thiết yếu làm giảm chi phí giao dịch của các khoản đầu tư, từ đó thúc đẩy dòng vốn FDI. Bên cạnh đó, FDI cũng bị ảnh hưởng bởi "niềm tin và sự tự tin" của các nhà đầu tư, về cơ bản là đề cập đến "nhận thức của các nhà đầu tư" về tài khóa của Chính phủ và các chính sách tiền tệ cũng như sự ổn định kinh tế vĩ mô của một quốc gia. Trên thực tế, không nhà đầu tư nào muốn đầu tư vào một quốc gia có hiệu quả quản trị nhà nước kém, tham nhũng vì sẽ làm tăng chi phí giao dịch và rủi ro bị quốc hữu hóa tài sản. Do đó, hiệu quả quản trị nhà nước là một yếu tố quan trọng tác động tích cực đến thu hút FDI.

Theo Kurul and Yalta (2017), ngày càng có nhiều nghiên cứu thực nghiệm xem xét vai trò của thể chế đối với dòng vốn FDI. Các yếu tố thể chế thường được xem xét là yếu tố chính trị và tham nhũng. Cụ thể, quốc gia có chỉ số tham nhũng cao sẽ làm tăng chí phí và tăng rủi ro cho các công ty đa quốc gia. Các quốc gia dân chủ thu hút được nhiều vốn FDI hơn các quốc gia độc tài do giảm thiểu rủi ro việc quốc hữu hóa và trưng thu tài sản từ Chính phủ, giúp tăng uy tín của quốc gia đối với các nhà đầu tư nước ngoài. Tuy nhiên, cũng có ý kiến cho 
rằng các quốc gia dân chủ kém hấp dẫn nhà đầu tư nước ngoài do chi phí lao động cao hơn, sức ép từ liên đoàn lao động. Đồng thời, các tác giả cũng nhấn mạnh việc thiếu vắng nhà nước pháp quyền, bất ổn về chính trị là những yếu tố ngăn cản dòng vốn FDI. Đồng thời, theo Biro et al. (2019), mặc dù chưa có bằng chứng chắc chắn về cách thức và mức độ ảnh hưởng của hiệu quả quản trị nhà nước đến dòng vốn FDI nhưng nhóm tác giả cho rằng hiệu quả quản trị nhà nước thông qua các khía cạnh tư pháp và pháp luật độc lập, luật pháp được thực thi công bằng và minh bạch, thông tin về tài chính công đáng tin cậy và lòng tin của công chúng sẽ giúp giảm chi phí, giảm rủi ro cho các nhà đầu tư nước ngoài, thông qua đó thu hút được nhiều vốn đầu tư hơn.

Nghiên cứu của Shah and Afridi (2015) được thực hiện với mục đích phân tích tác động của hiệu quả quản trị nhà nước đối với nguồn vốn FDI tại 5 quốc gia SAARC trong giai đoạn 2006-2014. Mặc dù kết quả nghiên cứu đã chỉ ra hầu hết các yếu tố cấu thành nên hiệu quả quản trị nhà nước đều có tác động tích cực đển thu hút FDI, tuy nhiên kết quả nghiên cứu cũng cho thấy biến số đo lường kiểm soát tham nhũng có tác động tiêu cực đến thu hút FDI. Tương tự như trên, các nghiên cứu của Gangi and Abdulrazak (2012), Ross (2019), Younsi and Bechtini (2019), Zidi and Ali (2016) cũng chỉ ra biến số đo lường kiểm soát tham nhũng có tác động tiêu cực đến thu hút FDI. Bên cạnh biến số đo lường kiểm soát tham nhũng, kết quả nghiên cứu của Gangi and Abdulrazak (2012), Ross (2019), Younsi and Bechtini (2019) còn cho thấy biến số đo lường quyền phát ngôn và trách nhiệm giải trình cũng có thể có tác động tiêu cực đến thu hút FDI. Ngoài những yếu tố kể trên, ổn định chính trị và không bạo động cũng là yếu tố có thể có tác động tiêu cực đến thu hút FDI (Ross, 2019; Zidi \& Ali, 2016).

Mặc dù đa số các nghiên cứu thực nghiệm đều cho thấy hiệu quả quản trị nhà nước đều có tác động tích cực đến thu hút FDI. Tuy nhiên, bên cạnh một số yếu tố cấu thành nên hiệu quả quản trị nhà nước có tác động dương, vẫn có một số yếu tố tác động âm, hoặc không có tác động đển thu hút FDI. Trong nghiên cứu của Shah and Afridi (2015), các tác giả đã không tìm thấy bằng chứng thực nghiệm cho thấy hiệu quả chính quyền, pháp quyền, quyền phát ngôn và trách nhiệm giải trình có tác động đến thu hút FDI. Hay trong nghiên cứu của Biro et al. (2019), Gangi and Abdulrazak (2012), Kurul and Yalta (2017), các tác giả đã không tìm thấy tác động của biến ồn định chính trị và không bạo động đến thu hút FDI. Tương tự, biến chất lượng điều hành cũng không có tác động đến thu hút FDI trong trường hợp nghiên cứu của Gangi and Abdulrazak (2012), Kurul and Yalta (2017), Mengistu and Adhikary (2011). Đồng thời, tương tự như nghiên cứu của Shah and Afridi (2015), các nghiên cứu của Biro et al. (2019), Gangi and Abdulrazak (2012), Kurul and Yalta (2017) cũng không cho thấy các biến số đo lường hiệu quả chính quyền, pháp quyền, quyền phát ngôn và trách nhiệm giải trình có tác động đến thu hút FDI.

\section{PHƯƠNG PHÁP NGHIÊN CÚU}

\subsection{Dữ liệu và phương pháp phân tích dữ liệu}

Dữ liệu sử dụng trong nghiên cứu này là dữ liệu thứ cấp của 11 quốc gia Đông Nam Á được thu thập trong giai đoạn 2000 đến 2018. Nguồn dữ liệu được thu thập từ WorldBank. Do dữ liệu của một số quốc gia tại một số thời điểm không có trong dữ liệu của WorldBank nên đây là dạng dữ liệu bảng không cân bằng (unbalanced panel).

Những phương pháp ước lượng cơ bản khi hồi quy với dữ liệu bảng bao gồm: Pooled OLS, Fixed effect model (FEM), Random effect model (REM). Bên cạnh đó, để kết quả ước lượng là đáng tin cậy thì mô hình cần đáp ứng một số giả định như: không có đa cộng tuyến, không có hiện tượng tự tương quan và phương sai sai số thay đổi. Đối với vấn đề đa cộng tuyến, nghiên cứu sử dụng ma trận hệ số tương quan để kiểm tra. Đồng thời, nghiên cứu sử dụng kiểm định Wald test để kiểm định hiện tượng phương sai sai số thay đổi và kiểm định Wooldridge test để kiểm định hiện tượng tự tương quan trong mô hình nghiên cứu. Trường hợp kết quả kiểm định mô hình có hiện tượng tự tương quan hoặc hiện tượng phương sai sai số thay đổi thì phương pháp ước lượng Generalized Least Squares (GLS) được vận dụng để khắc phục 2 hiện tượng này.

\subsection{Mô hình nghiên cứu}

Kế thừa mô hình nghiên cứu đã được sử dụng trong các nghiên cứu của Gani (2007), Mengistu and Adhikary (2011) và Shah and Afridi (2015), mô hình nghiên cứu xem xét tác động của hiệu quả quản trị nhà nước đến việc thu hút dòng vốn FDI ở các quốc gia Đông Nam Á trong giai đoạn 2000-2018 được đề xuất như sau:

$$
\begin{aligned}
\operatorname{lnFDI} & =\beta_{\text {it }}+\beta_{1} \text { market size }_{i t}+\beta_{2} \text { economic } \\
& \text { growth }_{\text {it }}+\beta_{3} \text { infrastructure }_{\text {it }}+\beta_{4} \text { natural } \\
& \text { resources }_{\text {it }}+\beta_{5} \text { domestic investment }_{\text {it }}+ \\
& \beta_{6} \text { openness }_{\text {it }}+\beta_{7} \mathrm{VA}_{\mathrm{it}}+\beta_{8} \mathrm{PSAV}_{\mathrm{it}}+ \\
& \beta_{9} \mathrm{GE}_{\mathrm{it}}+\beta_{10} \mathrm{RQ}_{\mathrm{it}}+\beta_{11} \mathrm{RL}_{\mathrm{it}}+\beta_{12} \mathrm{CC}_{\mathrm{it}} \\
& +\mathrm{f}_{\mathrm{i}}+\gamma_{t}+\mu_{\mathrm{it}}
\end{aligned}
$$


Trong đó:

InFDI: Phản ánh dòng vốn FDI ròng đi vào các nước (đơn vị là USD). Biến được lấy logarit tự nhiên nhằm giảm bớt sự chênh lệch quá lớn về quy mô dòng vốn FDI làm ảnh hưởng đến kết quả ước lượng mô hình. Cách đo lường này đã được sử dụng trong các nghiên cứu của Bénassy-Quéré et al. (2007), Biro et al. (2019), Globerman and Shapiro (2002), Li and Filer (2007), Mengistu and Adhikary (2011), Ross (2019), Shah (2014), Shah and Afridi (2015), Younsi and Bechtini (2019), Zeshan and Talat (2014).

market size: Phản ánh quy mô thị trường, đo lường bằng GDP của quốc gia (đơn vị là USD). Tương tự như FDI, biến này được lấy logarit tự nhiên. Cách đo lường quy mô thị trường này đã được sử dụng trong các nghiên cứu của Bénassy-Quéré et al. (2007), Biro et al. (2019), Gani (2007), Globerman and Shapiro (2002), Li and Filer (2007), Mengistu and Adhikary (2011), Younsi and Bechtini (2019). Lý thuyết tăng trưởng nội sinh cho rằng các quốc gia có quy mô thị trường lớn thường được kỳ vọng sẽ tăng trưởng nhanh hơn vì được hưởng lợi ích của lợi thế kinh tế theo quy mô. Do đó, FDI sẽ có xu hướng đổ vào các quốc gia có quy mô thị trường lớn hơn, vì một thị trường lớn tạo cơ hội cho các nhà đầu tư nước ngoài có thể hưởng mức chi phí sản xuất trên mỗi đơn vị sản phẩm cũng như chi phí phân phối thấp hơn nên quy mô thị trường được kỳ vọng tác động dương $(+)$ đến dòng vốn FDI.

economic growth: Phản ánh tốc độ tăng trưởng kinh tế, đo lường bằng tốc độ tăng GDP của quốc gia (đơn vị là \%). Cách đo lường này đã được sử dụng trong các nghiên cứu của Gani (2007), Kurul and Yalta (2017), Mengistu and Adhikary (2011), Ross (2019), Zidi and Ali (2016). Tốc độ tăng trưởng kinh tế cao phản ánh sự ổn định, vững chắc của nền kinh tế. Bên cạnh đó, tăng trưởng kinh tế tốt cũng thể hiện đời sống của người dân tốt, nên tăng trưởng kinh tế được kỳ vọng sẽ có tác động dương (+) đến dòng vốn FDI.

infrastructure: Phản ánh cơ sở hạ tầng của quốc gia. Đo lường bằng số lượng điện thoại/100 dân. Cách đo lường cơ sở hạ tầng thông qua chỉ tiêu số lượng điện thoại/100 dân đã được sử dụng trong các nghiên cứu của Kok and Ersoy (2009), Mengistu and Adhikary (2011), Shah (2014). Một quốc gia có cơ sở hạ tầng tốt sẽ giảm thiểu chi phí kinh doanh bằng cách giúp tăng giờ lao động hiệu quả nên cơ sở hạ tầng được kỳ vọng có tác động dương $(+)$ đến dòng vốn FDI. natural resources: Phản ánh nguồn lực tài nguyên thiên nhiên, đo lường bằng tổng giá trị thuê tài nguyên thiên nhiên/GDP (đơn vị là \%). Cách đo lường tài nguyên thiên nhiên của quốc gia như trên đã được vận dụng trong các nghiên cứu của Ross (2019). Sự phong phú của tài nguyên thiên nhiên sẽ thúc đẩy các công ty nước ngoài tham gia đầu tư vào các lĩnh vực khác nhau nên được kỳ vọng có tác động dương $(+)$ đến dòng vốn FDI.

domestic investment: Phản ánh lượng vốn đầu tư trong nước, đo lường bằng tổng vốn cố định của quốc gia/GDP (đơn vị là \%). Cách đo lường này đã được sử dụng trong các nghiên cứu của Kok and Ersoy (2009), Mengistu and Adhikary (2011), Zidi and Ali (2016). Một số nghiên cứu cho thấy FDI sẽ lấn át đầu tư trong nước, tuy nhiên một số khác lại chỉ ra 2 dòng vốn này có tương quan cùng chiều. Lý giải cho vấn đề này là do khi dòng vốn trong nước cao, chứng tỏ các doanh nghiệp tư nhân trong nước cũng lớn manh, đủ sức liên kêt, làm đối tác với các doanh nghiệp FDI, từ đó tạo điều kiện thuận lợi cho doanh nghiệp FDI khi hoạt động. Ngoài ra, khi dòng vốn trong nước cao cũng phản ánh môi trường đầu tư kinh doanh ở quốc gia này khá thuận lợi nên vốn đầu tư trong nước được kỳ vọng có tác động dương $(+)$ đến vốn FDI.

openness: Phản ánh độ mở của nền kinh tế, tổng khối lượng giao dịch thương mại (xuất nhập khẩu) theo \%GDP (đơn vị là \%). Cách đo lường độ mở của nền kinh tế này đã được sử dụng trong các nghiên cứu của Gani (2007), Kok and Ersoy (2009), Kurul and Yalta (2017), Li and Filer (2007), Shah (2014), Shah and Afridi (2015), Younsi and Bechtini (2019). Mức độ mà một quốc gia được liên kết với thế giới bên ngoài và cho phép nhập khẩu nguyên liệu thô và xuất khẩu thành phẩm là rất quan trọng đối với hoạt động kinh doanh của các công ty đa quốc gia, và điều này sẽ kích thích đầu tư nên độ mở của nền kinh tế được kỳ vọng có tác động dương $(+)$ đến dòng vốn FDI.

VA: Quyền phát ngôn và trách nhiệm giải trình. Biến này thể hiện khả năng tham gia của người dân trong việc bầu cử cũng như tự do ngôn luận và tự do truyền thông.

PSAV: Ổn định chính trị và không bạo động. Sự ổn định chính trị được hiểu là mức độ mà Chính phủ của quốc gia luôn trong tình trạng ổn định (Shah \& Afridi, 2015). Nếu quốc gia có những bất ổn chính trị, Chính phủ tại vị có nguy cơ bị giải thể. Các công ty đa quốc gia thường đầu tư vào các quốc gia dân chủ với các chính sách ổn định, thân thiện với doanh 
nghiệp, và hỗ trợ các khoản đầu tư và kinh doanh quốc tế của doanh nghiệp.

GE: Hiệu quả chính quyền. Một Chính phủ được cho là có hiệu quả nếu người dân được cung cấp dịch vụ chất lượng tốt nhất và cuộc sống của họ không bị áp lực chính trị (Shah \& Afridi, 2015). Các Chính phủ hiệu quả có thể tạo điều kiện tốt hơn cho các hoạt động của công ty đa quốc gia.

RQ: Chất lượng điều hành. Chất lượng điều hành cho thấy khả năng của Chính phủ trong việc xây dựng các chính sách hợp lý cho phát triển khu vực tư nhân. Nói cách khác, biến chất lượng điều hành đo lường các chính sách thân thiện với thị trường như bỏ kiểm soát giá hoặc giám sát ngân hàng không hiệu quả cũng như các nỗ lực khác để giảm bớt các quy định quá mức trong các lĩnh vực phát triển kinh doanh và ngoại thương.

RL: Pháp quyền. Chỉ số này cho thấy chất lượng thực thi hợp đồng cũng như khả năng phạm tội và bạo lực. Pháp quyền theo nghĩa rộng bao gồm một hệ thống pháp lý hiệu quả, vô tư và minh bạch, bảo vệ tài sản và quyền cá nhân; các tổ chức công cộng ồn định, đáng tin cậy và trung thực; và các chính sách của Chính phủ ủng hộ thị trường mở.

CC: Kiểm soát tham nhũng. Kiểm soát tham nhũng cho thấy mức độ phổ biến của tham nhũng trong chính phủ và khả năng của quan chức để có được những "lại quả" (kickback) thông qua việc khai thác vị trí của họ.

\section{KÊT QUẢ NGHIÊN CÚU}

\subsection{Thống kê mô tả và hệ số tương quan các biến trong mô hình nghiên cứu}

Kết quả thống kê mô tả trong Bảng 1 cho thấy dòng vốn FDI ròng vào các quốc gia Đông Nam Á trong giai đoạn 2000-2018 bình quân là 8,3 tỷ USD, cao nhất là 94,8 tỷ USD và thấp nhất là 0,005 tỷ USD. Quy mô nền kinh tế của các quốc gia bình quân là 169,1 tỷ USD; quốc gia có quy mô nền kinh tế lớn nhất đạt 1.015,4 tỷ USD và quốc gia có quy mô kinh tế nhỏ nhất là 0,5 tỷ USD. Bên cạnh đó, tốc độ tăng trưởng bình quân của các quốc gia đạt 5,2\%, quốc gia có tốc độ tăng trưởng kinh tế cao nhất lên đến $20,625 \%$ và thấp nhất là $-25,9 \%$. Kết quả thống kê mô tả cho thấy, trong giai đoạn nghiên cứu, yếu tố cơ sở hạ tầng được phản ánh thông qua số lượng điện thoại trên 100 dân của các quốc gia khu vực Đông Nam Á bình quân là 11,2/100 dân, thấp nhất là $0,1 / 100$ dân và cao nhất là $48,3 / 100$ dân. Nguồn lực tài nguyên thiên nhiên được phản ánh thông qua tổng giá trị thuê tài nguyên thiên nhiên/GDP của một quốc gia trong giai đoạn nghiên cứu bình quân đạt $10,2 \%$, thấp nhất là $0 \%$ và cao nhất là $74,1 \%$. Lượng vốn đầu tư trong nước phản ánh thông qua tổng vốn cố định của quốc gia/GDP bình quân đạt $24,1 \%$, thấp nhất là $3,4 \%$ và cao nhất là $35,1 \%$. Độ mở thương mại được phản ánh thông qua tổng khối lượng giao dịch thương mại (xuất nhập khẩu)/GDP bình quân đạt $134,9 \%$, thấp nhất là $0,1 \%$ và cao nhất là $437,3 \%$.

Kết quả thống kê hiệu quả quản trị nhà nước của các quốc gia Đông Nam Á thông qua sáu chỉ số thành phần của bộ chỉ số quản trị toàn cầu WGIs (nằm trong khoảng $-2,5$ đến $+2,5$ ) cho thấy, chỉ số phản ánh quyền phát ngôn và trách nhiệm giải trình bình quân đạt $-0,6$, thấp nhất là $-2,2$ và cao nhất là 0,4 ; sự ổn định chính trị và không có bạo lực bình quân đạt $-0,1$, thấp nhất là $-1,9$ và cao nhất là 1,6 ; hiệu quả chính quyền bình quân đạt 0,05 , thấp nhất là $-1,6$ và cao nhất là 2,4 ; chất lượng điều hành bình quân đạt $-0,05$, thấp nhất là $-2,2$ và cao nhất là 2,2 ; pháp quyền bình quân đạt $-0,2$, thấp nhất là $-1,5$ và cao nhất là 1,8 ; khả năng kiểm soát tham nhũng bình quân đạt $-0,2$, thấp nhất là $-1,6$ và cao nhất đạt 2,3 .

Song song đó, kết quả phân tích hệ số tương quan giữa các biến giải thích cho thấy hệ số tương quan giữa các biến hiệu quả chính quyền, chất lượng điều hành, pháp quyền, kiểm soát tham nhũng là khá cao (lớn hơn 0,9$)$. Khi hệ số tương quan giữa các cặp biến này cao là dấu hiệu của hiện tượng đa cộng tuyến trong mô hình. Để giải quyết vấn đề này, Gani (2007) đã lần lượt đưa từng chỉ số thành phần vào mô hình hồi quy để ước lượng. Kế thừa nghiên cứu của Gani (2007), nghiên cứu cũng lần lượt đưa các chỉ số thành phần phản ánh hiệu quả quản trị nhà nước vào mô hình để ước lượng theo hướng không đưa đồng thời các biến có hệ số tương quan cao với nhau vào cùng một mô hình hồi quy. 
Bảng 1. Kết quả thống kê mô tả các biến trong mô hình nghiên cứu

\begin{tabular}{|c|c|c|c|c|c|c|}
\hline Nội dung & Đơn vị & $\begin{array}{r}\text { Số } \\
\text { quan sát } \\
\end{array}$ & $\begin{array}{r}\text { Trung } \\
\text { bình } \\
\end{array}$ & $\begin{array}{r}\text { Độ lệch } \\
\text { chuẩn }\end{array}$ & \multicolumn{2}{|c|}{$\begin{array}{l}\text { Nhỏ Lớn nhất } \\
\text { nhất }\end{array}$} \\
\hline $\begin{array}{l}\text { FDI } \\
\text { (Đầu tu trục tiếp nước ngoài) }\end{array}$ & Tỷ USD & 168 & 8,345 & 15,117 & 0,005 & 94,811 \\
\hline $\begin{array}{l}\text { GDP } \\
\text { (Tổng sản phẩm quốc nội) }\end{array}$ & Tỷ USD & 168 & 169,157 & 209,991 & 0,5431 & $.015,420$ \\
\hline $\begin{array}{l}\text { economic growth } \\
\text { (Tăng trương kinh tê) }\end{array}$ & $\%$ & 168 & 5,223 & 4,369 & $-25,907$ & 20,625 \\
\hline $\begin{array}{l}\text { infrastructure } \\
\text { (Co sơ ha tầng) }\end{array}$ & $\begin{array}{l}\text { Điện thoại/ } \\
100 \text { dân }\end{array}$ & 168 & 11,291 & 11,883 & 0,190 & 48,301 \\
\hline $\begin{array}{l}\text { natural resources } \\
\text { (Tài nguyên thiên nhiên) }\end{array}$ & $\%$ & 168 & 10,233 & 13,415 & 0,0003 & 74,131 \\
\hline $\begin{array}{l}\text { domestic investment } \\
\text { (Đầu tur trong nước) }\end{array}$ & $\%$ & 168 & 24,126 & 6,131 & 3,487 & 35,107 \\
\hline $\begin{array}{l}\text { openness } \\
\text { (Đố mở thuong mai) } \\
\text { VA }\end{array}$ & $\%$ & 168 & 134,921 & 91,137 & 0,167 & 437,326 \\
\hline $\begin{array}{l}\text { (Quyền phát ngôn và trách nhiệm giải } \\
\text { trình) }\end{array}$ & & 168 & $-0,630$ & 0,665 & $-2,207$ & 0,467 \\
\hline $\begin{array}{l}\text { PSAV } \\
\text { (Ốn định chính trị và không có bạo lục) }\end{array}$ & & 168 & $-0,175$ & 0,890 & $-1,908$ & 1,615 \\
\hline $\begin{array}{l}\text { GE } \\
\text { (Hiệu quả chính quyền) }\end{array}$ & & 168 & 0,055 & 1,015 & $-1,617$ & 2,436 \\
\hline $\begin{array}{l}\text { RQ } \\
\text { (Chất lương điều hành) }\end{array}$ & & 168 & $-0,058$ & 0,984 & $-2,244$ & 2,260 \\
\hline $\begin{array}{l}\text { RL } \\
\text { (Pháp quyền) }\end{array}$ & & 168 & $-0,243$ & 0,873 & $-1,547$ & 1,825 \\
\hline $\begin{array}{l}\mathbf{C C} \\
\text { (Kiểm soát tham nhũng) }\end{array}$ & & 168 & $-0,260$ & 0,975 & $-1,672$ & 2,325 \\
\hline
\end{tabular}

Nguồn: Tổng hợp tù số liệu WorldBank

\subsection{Kết quả hồi quy mô hình nghiên cứu}

Kết quả ước lượng mô hình nghiên cứu dựa trên dữ liệu sử dụng trong nghiên cứu được thu thập từ 11 quốc gia Đông Nam Á trong khoảng thời gian 2000 - 2018 bằng 04 phương pháp Pooled OLS, Fixed effect, Random effect và GLS. Khi thực hiện hồi quy Fixed effect và Random effect đối với các mô hình, kết quả các kiểm định $\mathrm{F}$ đều có $\mathrm{p}$-value < 0,05 , và kết quả kiểm định Hausman test $\mathrm{p}$-value < 0,05 nên trong số 3 phương pháp Pooled OLS, Fixed effect, Random effect thì phương pháp ước lượng Fixed effect là phù hợp. Kêt quả các kiểm định Wald test đều có $p$-value $<0,05$ và kiểm định Wooldridge test đều có $p$-value $>0,05$ nên mô hình có hiện tượng phương sai thay đổi nhưng không có hiện tượng tự tương quan. Do đó, trong trường hợp này thì phương pháp ước lượng GLS là phù hợp để giải thích tác động của các biến giải thích đến thu hút vốn FDI.

Kết quả ước lượng trong Bảng 2 cho thấy, trong số các chỉ số phản ánh hiệu quả quản trị nhà nước, sự ổn định chính trị và không có bạo lực là yếu tố có tác động tích cực đến thu hút vốn FDI. Kết quả nghiên cứu này cũng tương đồng với nghiên cứu của Bénassy-Quéré et al. (2007), Biro et al. (2019), Gangi and Abdulrazak (2012), Gani (2007), Globerman and Shapiro (2002), Kurul and Yalta (2017), Li and Filer (2007), Mengistu and Adhikary (2011), Ross (2019), Shah and Afridi (2015), Younsi and Bechtini (2019), Zeshan and Talat (2014). Đối với những quốc gia không ổn định chính trị và có bạo lực thì nguy cơ cao Chính phủ cầm quyền sẽ thiếu ổn định hoặc có khả năng bị lật đổ bởi những hành vi vi hiến như bạo động, khủng bố. Sự ổn định chính trị là điều cần thiết thúc đẩy việc phân bổ nguồn lực hiệu quả và tăng cường lòng tin cho các nhà đầu tư dài hạn, đồng thời, các công ty đa quốc gia không muốn đầu tư vào những thị trường có độ rủi ro cao.

Tuy nhiên, kết quả hồi quy lại cho thấy hiệu quả chính quyền có tác động tiêu cực đến thu hút vốn FDI. Kết quả này là chưa tương đồng với kết quả 
nghiên cứu của Kaufmann et al. (1999), Shah and Afridi (2015). Bởi theo các tác giả trên thì các Chính phủ hiệu quả có thể tạo điều kiện tốt hơn cho các hoạt động của công ty đa quốc gia. Tuy nhiên, đối với những quốc gia có chính quyền càng hiệu quả thì các công ty đa quốc gia cũng phải đáp ứng các yêu cầu cao, như chi phí mức lương cho người lao động, điều kiện, chế độ đãi ngộ cho người lao động, yêu cầu về bảo vệ môi trường, đóng góp cho an sinh xã hội. Những yếu tố này có khả năng làm tăng chi phí hoạt động của các công ty đa quốc gia do những quốc gia có chính quyền hiệu quả sẽ bảo hộ tốt cho công dân và doanh nghiệp của họ. Đồng thời, sự chi tiết, phức tạp của hệ thống quản lý, của pháp luật ở nước nhận đầu tư cũng đòi hỏi các nhà đầu tư nước ngoài phải có năng lực thích nghi, năng lực hấp thụ tốt với hệ thống thể chế và cần có thời gian để thẩm thấu. Điều này dẫn đến dòng vốn FDI chảy vào các quốc gia có chính quyền hiệu quả ít hơn những quốc gia khác.

Ngoài ra, quyền phát ngôn và trách nhiệm giải trình cũng là yếu tố có tác động tiêu cực đến thu hút vốn FDI. Kết quả này có thể xuất phát từ nguyên nhân do cạnh tranh trong thu hút vốn FDI, các quốc gia Đông Nam Á đã hạ thấp tiêu chuẩn chất lượng trong thu hút FDI, dẫn đến thu hút các doanh nghiệp FDI có trình độ công nghệ sản xuất trung bình, tiêu tốn nhiều tài nguyên thiên nhiên, lượng phát thải lớn (Phạm Thị Ngoan, 2019). Tuy nhiên, khi quyền phát ngôn của người dân và trách nhiệm giải trình của chính quyền được nâng lên, người dân ở quốc gia nhận đầu tư sẽ có nhiều cơ hội thể hiện quan điểm không chấp nhận dòng vốn FDI kém chất lượng và Chính phủ phải có trách nhiệm nâng cao chất lượng thu thú FDI, nên đã làm hạn chế các dòng vốn FDI truyền thống đầu tư vào khu vực Đông Nam Á. Kết quả này cũng tương đồng với nghiên cứu của Gangi and Abdulrazak (2012), Ross (2019), Younsi and Bechtini (2019). Ngoài ba yếu tố kể trên, kết quả nghiên cứu cũng chỉ ra yếu tố đo lường chất lượng điều hành, pháp quyền và kiểm soát tham nhũng là những yếu tố không có tác động đến thu hút vốn FDI trong trường hợp ở các quốc gia Đông Nam Á trong giai đoạn 2000-2018.

Song song đó, kết quả ước lượng cho thấy, tác động của các biến kiểm soát đến biến phụ thuộc là khá ổn định khi thay đổi các yếu tố đo lường hiệu quả quản trị nhà nước. Theo đó, quy mô thị trường có tác động tích cực đến thu hút vốn FDI, tức là quy mô thị trường càng lớn thì càng thu hút được nhiều vốn FDI. Trên thực tế, khi quy mô thị trường càng lớn thì chi phí của các công ty đa quốc gia sẽ được cắt giảm nếu các cơ sở sản xuất hoặc phân xưởng của họ đặt tại chính thị trường tiêu thụ này. Bên cạnh đó, đổi với những thị trường có quy mô lớn sẽ thu hút được nhiều nhà sản xuất khác nhau hội tụ về thị trường này, qua đó giúp tăng cường sự liên kết, giảm thiểu chi phí giao dịch giữa các nhà sản xuất với nhau, đồng thời là sự sẵn có của các yếu tố đầu vào với mức độ chuyên môn hóa cao. Tất cả những yếu tố kể trên sẽ tạo ra lực hút các công ty đa quốc gia, qua đó làm tăng dòng vốn FDI vào những quốc gia có quy mô thị trường lớn. Kết quả nghiên cứu cũng tương đồng với kết quả nghiên cứu của BénassyQuéré et al. (2007), Biro et al. (2019), Gani (2007), Globerman and Shapiro (2002), Li and Filer (2007), Mengistu and Adhikary (2011), Younsi and Bechtini (2019).

Tốc độ tăng trưởng kinh tế cũng là yếu tố có tác động tích cực đến thu hút vốn FDI. Điều này chứng tỏ một quốc gia có tốc độ tăng trưởng kinh tế tốt sẽ thu hút được nhiều vốn FDI hơn. Những quốc gia có tốc độ tăng trưởng cao sẽ khuyến khích các công ty đa quốc gia tăng cường đầu tư để tìm kiếm lợi nhuận bởi tốc độ tăng trưởng kinh tế cao sẽ mang lại cơ hội lợi nhuận cao hơn cho các công ty đa quốc gia. Đồng thời quốc gia có tốc độ tăng trưởng tốt cũng phản ánh sự ổn định và hiệu quả của các chính sách kinh tế do Chính phủ điều hành và phản ánh sức mua tốt của thị trường, chính điều này đã làm tăng dòng vốn FDI đầu tư vào các quốc gia có tốc độ tăng trưởng kinh tế cao. Kết quả nghiên cứu cũng tương đồng với kết quả nghiên cứu của Gani (2007), Kurul and Yalta (2017), Mengistu and Adhikary (2011), Ross (2019), Zidi and Ali (2016). Nguồn lực tài nguyên thiên nhiên là yếu tố có tác động tiêu cực đến thu hút vốn FDI. Trong nghiên cứu của Ross (2019), tác giả cho rằng nguồn lực tài nguyên thiên nhiên càng nhiều thì càng thu hút nhiều vốn FDI. Tuy nhiên, trong trường hợp của nghiên cứu, nguồn lực tài nguyên thiên nhiên được đo lường bằng chi phí của việc thuê mướn tài nguyên thiên nhiên, tổng số tiền thuê mướn tài nguyên thiên nhiên càng nhiều vừa phản ánh lượng tài nguyên thiên thiên phong phú vừa phản ánh số tiền mà các doanh nghiệp FDI phải bỏ ra để thuê tài nguyên thiên nhiên cao, điều này làm tăng chi phí, giảm bớt lợi nhuận của các công ty đa quốc gia. Chính việc chi phí phải bỏ ra cao đã khiến các doanh nghiệp FDI ngần ngại khi đầu tư, làm giảm dòng vốn FDI chảy vào những quốc gia có chi phí của việc thuê mướn tài nguyên thiên nhiên cao.

Vốn đầu tư trong nước là một yếu tố có tác động tích cực đến thu hút vốn FDI. Kết quả của nghiên cứu cũng tương đồng với kết quả nghiên cứu của Kurul and Yalta (2017), Mengistu and Adhikary 
(2011), Zidi and Ali (2016). Trên thực tế, các công ty đa quốc gia khi đầu tư FDI có thể hợp tác, liên doanh với các doanh nghiệp nội địa. Khi liên doanh hợp tác, cần sự chia sẻ chi phí đầu tư trong quá trình hoạt động sản xuất kinh doanh cho những dự án lớn.
Việc lượng vốn đầu tư trong nước càng cao chứng tỏ các công ty nội địa có năng lực tài chính và năng lực quản lý tài chính cao. Điều này sẽ tạo điều kiện thuận lợi cho quá trình hợp tác, do đó thúc đẩy việc các công ty đa quốc gia đầu tư FDI.

Bảng 2. Tác động của hiệu quả quản trị nhà nước đến việc thu hút dòng vốn FDI ở các quốc gia Đông Nam Á trong giai đoạn 2000-2018

\begin{tabular}{|c|c|c|c|c|}
\hline & $\begin{array}{l}\text { InFDI } \\
(\text { GSL) } \\
\end{array}$ & $\begin{array}{l}\text { InFDI } \\
\text { (GSL) } \\
\end{array}$ & $\begin{array}{l}\text { InFDI } \\
(\text { GSL) } \\
\end{array}$ & $\begin{array}{l}\text { InFDI } \\
(\text { GSL) } \\
\end{array}$ \\
\hline market size & $1,089 * * *$ & $1,035 * * *$ & $1,050 * * *$ & $1,034 * * *$ \\
\hline Ln (Tống sản phấm quốc nội) & $(22,54)$ & $(23,29)$ & $(22,00)$ & $(23,79)$ \\
\hline economic growth & $0,039 * *$ & $0,047 * * *$ & $0,043 * *$ & $0,043 * *$ \\
\hline (Tăng trương kinh tế) & $(2,78)$ & $(3,30)$ & $(2,95)$ & $(3,05)$ \\
\hline infrastructure & 0,014 & $-0,004$ & 0,005 & 0,004 \\
\hline (Co sơ hạ tầng) & $(1,40)$ & $(-0,41)$ & $(0,52)$ & $(0,40)$ \\
\hline natural resources & $-0,024 * * *$ & $-0,017 * *$ & $-0,022 * * *$ & $-0,019, * *$ \\
\hline (Tài nguyên thiên nhiên) & $(-4,12)$ & $(-2,70)$ & $(-3,58)$ & $(-3,29)$ \\
\hline domestic investment & 0,807 & $2,101 *$ & 1,337 & 1,757 \\
\hline (Đầu tur trong nước) & $(0,80)$ & $(2,19)$ & $(1,36)$ & $(1,90)$ \\
\hline openness & $0,004 * * *$ & $0,004 * * *$ & $0,004 * * *$ & $0,004 * * *$ \\
\hline (Độ mở thương mại) & $(4,59)$ & $(4,84)$ & $(4,67)$ & $(4,85)$ \\
\hline VA & $-0,135$ & $-0,296^{*}$ & $-0,203$ & $-0,208$ \\
\hline (Quyền phát ngôn và trách nhiệm giải trình) & $(-1,29)$ & $(-2,47)$ & $(-1,86)$ & $(-1,75)$ \\
\hline PSAV & $0,556 * * *$ & $0,365 * *$ & $0,483 * * *$ & $0,426 * * *$ \\
\hline (Ốn định chính trị và không có bạo lụcc) & $(5,04)$ & $(3,24)$ & $(3,97)$ & $(3,90)$ \\
\hline GE & $-0,429 * *$ & & & \\
\hline (Hiệu quả chính quyền) & $(-2,91)$ & & & \\
\hline RQ & & 0,052 & & \\
\hline (Chất lượng điều hành) & & $(0,38)$ & & \\
\hline RL , , & & & $-0,23$ & \\
\hline (Pháp quyền) & & & $(-1,32)$ & \\
\hline $\mathbf{C C}$ & & & & $-0,146$ \\
\hline (Kiềm soát tham nhũng) & & & & $(-0,83)$ \\
\hline _cons & $-6,540 * * *$ & $-5,607 * * *$ & $-5,790 * * *$ & $-5.546 * * *$ \\
\hline (Hằng số) & $(-5,56)$ & $(-5,05)$ & $(-4,89)$ & $(-5,05)$ \\
\hline $\mathbf{N}$ & 168 & 168 & 168 & 168 \\
\hline Wald $\operatorname{chi}^{2}(9)$ & $1.715,1$ & $1.843,6$ & $1.663,6$ & $1.781,1$ \\
\hline p-value & 0,000 & 0,000 & 0,000 & 0,000 \\
\hline
\end{tabular}

Độ mở của nền kinh tế có tác động tích cực đến thu hút vốn FDI. Kết quả nghiên cứu cũng tương đồng với kết quả nghiên cứu của Gani (2007), Kok and Ersoy (2009), Kurul and Yalta (2017), Li and Filer (2007), Shah (2014), Shah and Afridi (2015), Younsi and Bechtini (2019). Các tác giả cho rằng những quốc gia có độ mở nền kinh tế càng lớn thì tốc độ đổi mới, khả năng tăng trưởng kinh tế càng cao thông qua việc tiếp thu, học hỏi kinh nghiệm từ những quốc gia phát triển thông qua quá trình xuất nhập khẩu. Độ mở nền kinh tế càng lớn còn phản ánh khả năng lan tỏa công nghệ, khuếch tán công nghệ càng cao, qua đó thúc đầy tăng trưởng kinh tế, tạo động lực thu hút dòng vốn FDI.
Cơ sở hạ tầng trong trường hợp nghiên cứu này không có tác động đến thu hút vốn FDI. Tức là vấn đề cơ sở hạ tầng ở quốc gia sở tại chưa thật sự là vấn đề lớn để các doanh nghiệp FDI xem xét khi quyết định đầu tư. Kết quả này chưa tương đồng với kết quả nghiên cứu của Kok and Ersoy (2009), Mengistu and Adhikary (2011), Shah (2014). Quốc gia có cơ sở hạ tầng phát triển sẽ giúp giảm thiểu chi phí hoạt động cho các công ty đa quốc gia do đó các công ty có xu hướng đầu tư nhiều ở những quốc gia có cơ sở hạ tầng phát triển; đồng thời, để đo lường cơ sở hạ tầng có thể đo lường bằng nhiều cách thức khác nhau như chiều dài các tuyến đường bộ, đường sắt, mạng lưới cung cấp điện nước, viễn thông. 
Trong trường hợp các quốc gia ở Đông Nam Á đa phần là các quốc gia đang phát triển, có cơ sở hạ tầng mà cụ thể là mạng lưới viễn thông khá tương đồng nên không tạo ra sự khác biệt trong thu hút dòng vốn FDI. Các công ty đa quốc gia quan tâm đến quy mô thị trường, tiềm năng lợi nhuận khi đầu tư hơn là xem xét yếu tố cơ sở hạ tầng bởi yếu tố cơ sở hạ tầng ở các quốc gia Đông Nam Á là khá tương đồng với nhau.

\section{KẾT LUẪN VÀ HÀM Ý CHÍNH SÁCH}

\subsection{Kết luận}

Để đạt được mục tiêu nghiên cứu ảnh hưởng của quản trị nhà nước đến việc thu hút dòng vốn FDI ở các quốc gia Đông Nam Á trong giai đoạn 20002018, nghiên cứu đã vận dụng phương pháp phân tích tổng hợp để lược khảo các khái niệm, lý thuyết và các nghiên cứu thực nghiệm có liên quan đến vấn đề nghiên cứu, đặc biệt là kế thừa mô hình nghiên cứu đã được sử dụng trong các bài nghiên cứu của Gani (2007), Mengistu and Adhikary (2011) và Shah and Afridi (2015) để đề xuất mô hình nghiên cứu cho đề tài. Dữ liệu sử dụng trong nghiên cứu là dữ liệu thứ cấp từ WorldBank giai đoạn 2000 đến 2018. Các phương pháp phân tích hồi quy Pooled OLS, Fixed effect, Random effect và GLS cùng với các kiểm định F-test, Hausman test, Wald test, Wooldridge test được áp dụng để phân tích dữ liệu.

Kết quả nghiên cứu tác động của hiệu quả quản trị nhà nước đến thu hút vốn FDI ở các quốc gia Đông Nam Á trong giai đoạn 2000-2018 cho thấy, có một yếu tố trong bộ chỉ tiêu đo lường hiệu quả quản trị nhà nước có tác động tích cực đến thu hút vốn FDI là sự ổn định chính trị và không có bạo lực và hai yếu tố có tác động tiêu cực đến thu hút vốn FDI là quyền phát ngôn và trách nhiệm giải trình, và hiệu quả chính quyền. Ngoài 3 yếu tố kể trên, kết quả nghiên cứu còn cho thấy, quy mô thị trường, tốc độ tăng trưởng kinh tế, nguồn lực tài nguyên thiên nhiên, vốn đầu tư trong nước và độ mở của nền kinh tế cũng là những yếu tố có tác động đến thu hút vốn FDI ở các quốc gia Đông Nam Á trong giai đoạn 2000-2018.

\subsection{Hàm ý chính sách}

Kết quả nghiên cứu đã chỉ ra trong số sáu yếu tố thành phần đo lường hiệu quả quản trị nhà nước, hai yếu tố có tác động tiêu cực và một yếu tố có tác động tích cực đến thu hút dòng vốn FDI. Do đó, khi vận dụng bộ chỉ số WGIs vào quá trình hoạch định chính sách, cần xem xét, đánh giá cho từng trường hợp cụ thể, để có thể đưa các giải pháp, chính sách thu hút FDI phù hợp.
Trong trường hợp các quốc gia Đông Nam Á, cần tiếp tục tập trung giữ vững ổn định chính trị và không để xảy ra các vụ việc bạo lực, khủng bố nhằm tạo lòng tin, sự ổn định cho nhà đầu tư nước ngoài. Đồng thời, rà soát, nghiên cứu, điều chỉnh, bổ sung chính sách trong thu hút đầu tư $\mathrm{FDI}$, đảm bảo hài hòa giữa lợi ích của quốc gia, dân tộc, người dân trong nước, vừa đảm bảo lợi nhuận phù hợp cho các doanh nghiệp FDI.

\subsection{Hạn chế và hướng nghiên cứu tiếp theo}

Do dữ liệu nghiên cứu sử dụng trong nghiên cứu là dữ liệu thứ cấp được thu thập từ WorldBank nên dữ liệu thu thập được chưa đầy đủ (unbalanced panel data) và có độ trễ nên cũng đã góp phần làm hạn chế kết quả nghiền cứu. Bên cạnh đó, hiệu quả quản trị nhà nước được đo lường thông qua các chỉ số quản trị toàn cầu WGIs (Worldwide Governance Indicators) trong khi hiệu quả quản trị nhà nước có thể được đo lường bằng nhiều chỉ số khác nhau, tùy thuộc vào mục tiêu nghiên cứu như Chỉ số Năng lực cạnh tranh toàn cầu (Global Competitiveness Index - GCI), Chỉ số tự do kinh tế (Indices of Economic Freedom - IEF), Chỉ số cảm nhận tham nhũng (Corruption Perceptions Index - CPI).

Các nghiên cứu tiếp theo có thể thực hiện để nghiên cứu về tác động của hiệu quả quản trị nhà nước đến sự phát triển của từng ngành hàng cụ thể, hoặc đi sâu vào phân tích từ chỉ số thành phần của chỉ số quản trị nhà nước. Trong trường hợp tiếp tục nghiên cứu về thu hút vốn FDI, các nghiên cứu tiếp theo có thể bổ sung vào mô hình nghiên cứu những biến số giải thích liên quan đến yếu tố khác biệt văn hóa, hoặc các hiệp định thương mại song phương, đa phương của các quốc gia tác động đến thu hút vốn FDI.

\section{TÀI LIỆU THAM KHẢO}

Bénassy-Quéré, A., Coupet, M., \& Mayer, T. (2007). Institutional determinants of foreign direct investment. The World Economy, 30(5), 764-782.

Biro, F. P., Erdey, L., Gall, J., \& Markus, A. (2019). The effect of Governance on foreign direct investment in Latin America - Issues of model selection. Global Economy Journal, 19(1), 1-20.

Gangi, Y. A., \& Abdulrazak, R. S. (2012). The impact of governance on FDI flows to African countries. World Journal of Entrepreneurship, Management and Sustainable Development, 8(2), 162-169.

Gani, A. (2007). Governance and foreign direct investment links: Evidence from panel data estimations. Applied Economics Letters, 14(10), 753-756. 
Globerman, S., \& Shapiro, D. (2002). Global foreign direct investment flows: The role of governance infrastructure. World Development, 30(11), 1899-1919.

International Monetary Fund. (1993). Balance of Payments $\left(5^{\text {th }} \mathrm{ed}\right)$. International Monetary Fund.

International Monetary Fund. (2003). World economic outlook: Public debt in emerging markets. International Monetary Fund.

Kasper, W., \& Streit, M. E. (1998). Institutional Economics: Social Order and Public Policy. Edward Elgar.

Kaufmann, D., Kraay, A., \& Zoido, P. (1999). Aggregating governance indicators. Policy Research Working Papers 2195. https://doi.org/10.1596/1813-9450-2195

Kok, R., \& Ersoy, B. A. (2009). Analyses of FDI determinants in developing countries. International Journal of Social Economics, 36(1/2), 105-123.

Kurul, Z., \& Yalta, A. Y. (2017). Relationship between institutional factors and FDI flows in developing countries: New evidence from dynamic panel estimation. Economies, 5(2), 1-10.

Li, S., \& Filer, L. (2007). The effects of the governance environment on the choice of investment mode and the strategic implications. Journal of World Business, 42(1), 80-98.

Mengistu, A. A., \& Adhikary, B. K. (2011). Does good governance matter for FDI inflows? Evidence from Asian economies. Asia Pacific Business Review, 17(3), 281-299.

North, D. C. (1990). Institutions, Institutional Change and Economic Performance. Cambridge University Press.

Phạm Thị Ngoan. (2019, December 9). Mở cửa thu hút FDI và vấn đề môi truờng. http://tapchicongthuong.vn/bai-viet/mo-cua-thuhut-fdi-va-van-de-moi-truong-67227.htm

Ross, A. G. (2019). Governance infrastructure and FDI flows in developing countries. Transnational Corporations Review, 11(2), 109-119.

Shah, A., \& Huther, J. (1999). Applying a simple measure of good governance to the debate on fiscal decentralization. Policy Research Working Papers 1984. https://doi.org/10.1596/1813-9450-1894

Shah, M. H. (2014). The significance of infrastructure for FDI inflow in developing countries. Journal of Life Economics, 2, 1-16.

Shah, M. H., \& Afridi, A. G. (2015). Significance of Good Governance for FDI Inflows in SAARC Countries. Business \& Economic Review, 7(2), 31-52.

Wei, S.-J. (2000). How Taxing is Corruption on International Investors? The Review of Economics and Statistics, 82(1), 1-11.

World Trade Organization. (1996, October 14). Trade and foreign direct investment. https://www.wto.org/English/news_e/pres96_e/p r057_e.htm

Younsi, M., \& Bechtini, M. (2019). Does good governance matter for FDI? New evidence from emerging countries using a static and dynamic panel gravity model approach. Economics of Transition and Institutional Change, 27(3), 841-860.

Zeshan, A., \& Talat, A. (2014). Impact of Governance indicators on FDI inflows: Empirical evidence from Pakistan. Caspian Journal of Applied Sciences Research, 3(9), 16-23.

Zidi, A., \& Ali, T. BEN. (2016). Foreign Direct Investment (FDI) and Governance: The Case of MENA. Journal of Research in Business, Economics and Management, 5(3), 598-608. 